\title{
Enhancing Students' Use of Cohesive Devices: Impacts of PowerPoint Presentations on EFL Academic Writing
}

\author{
Soraya Rajabi \\ University of Isfahan, Iran \\ Email: soraya.rajabi2008@gmail.com \\ Saeed Ketabi \\ University of Isfahan, Iran \\ Email: ketabi@fgn.ui.ac.ir
}

\begin{abstract}
This study aims to explore the impacts of preparing and presenting PowerPoint slides in EFL settings on the improvement of cohesive devices in EFL setting. In order to examine the effects of PowerPoint presentations on students' use of cohesive devices, sixty two BA students from University of Isfahan were randomly assigned into 2 groups .The course was "advanced writing". Each session lasted 90 minutes. One group received the traditional textbook teaching style whereas the other group received the power points of the same materials during ten sessions. Comparing the performance of two groups based on use of cohesive devices, it became evident that students in power point group performed better than students in traditional teaching style. (Frequency use of cohesive devices in power point group is 47.79 and the frequency use of cohesive devices in traditional teaching style is 27.79). Also results indicated that preparing and presenting power point slides had a significant effect on students writing achievement and their appropriate use of cohesive devices.
\end{abstract}

Index Terms-PowerPoint presentation, EFL, cohesive devices, academic writing

\section{INTRODUCTION}

It seems that it is a Power Point world, surrounded by complete images, movement and sound.Technological advances have led to a boom in the use of multimedia presentations in college classrooms .Multimedia formats are popular with faculty and students alike .In fact, faculty and students think (i.e., perceive) that the use of multimedia presentations improves student learning (Hogarty, Lang, and Kromney 2003).

While the use of PowerPoint and multimedia in the classroom has significantly increased globally in recent years (Connor and Wong, 2004Bartsch and Cobern, 2003), it seems that few studies have systematically investigated its impact on student learning.

Rebele et al. (1998) note that little research exists regarding integration of technology in the curriculum, and suggests that researchers should examine whether technology improves learning. Further, Rebeleet (1998) recommend "researchers should explore how educational technology can contribute to the continuing evolution and improvement of education" (p. 207).

One study that has examined the relationship between multimedia and student learning and attitudes was conducted by Butler and Mautz (1996) in a laboratory experiment conducted during a 30-minute time period.The results showed an interaction between the effects of the multimedia presentation and the students' preferred class representation style (i.e., whether the student was considered a "verbal" or imaginal" learner).

Teachers have been using computers in EFL courses for many years and have employed a variety of computer applications and methodologies .Some agree with Murphy-Judy (1997)that "the readers whom foreign language education produces now, should not be trained in defunct literacy practices, but rather should be prepared to function in this new world".

It is believed that PowerPoint presentations incorporate graphics, animation, and color, imagery. Reynolds and Baker (1987) found that presenting materials on a computer increased attention and learning, and learning increased as attention increased

In 2002, it was estimated that more than 400 million copies of Power Point presentations were in circulation and that somewhere between 20 and 30 million power point based presentations were given around the globe each day. (Simons 2005).

EFL practitioners using Power Point slides consider Power Point presentation as a process consisting of six main stages:

a. Preparation stage 
b. Material collection and arrangements

c. Rehearsal stage

d. Delivery stage

e. Follow-up stage

f. Evaluation and assessment stage

Since few studies have systematically investigated Power Points' presentations impacts on EFL settings, the present study made an attempt to explore and address it .In fact, the question the present study sought to address was this :"it is generally assumed that the modern technology significantly improves learning."

\section{REVIEW OF LITERATURE}

Researches exploring the effect of preparing powerpoint presentations by students seem to be very limited .Gunel (2006) compared the effectiveness of writing summary report and preparing PowerPoint presentation on students 'achievements on two units in physics lesson.The results indicated that students preparing the PowerPoint presentation scored significantly better on achievement test than the summary report format group .In another study, he(2006) investigated the students' ability to choose the material and the content of PowerPoint presentations on professional topics via the internet as well as the ability to prepare and deliver the presentation in front of the audience .At the result, it was reported that preparing and delivering PowerPoint presentation improved students listening, speaking, reading and writing skills.

PowerPoint presentations should arouse the imagery system and could contribute to comprehension, and improve short and long-term memory .Since, in a PowerPoint presentation, topics are presented in a hierarchical fashion with graphics, color, and animation, students could "use a mental image of that outline to study, to retrieve the information on a test, to organize their answer for an essay question, and to perform other educational tasks (Clark and Paivio, 1991. p. 176). " Rose (2001) also notes that presentation of learning materials in graphical form is beneficial for students.

In power points slides, Peek (1987) found that when pictures and text are presented together, information retention is improved. Other studies have shown that color is a factor in memory representation .For example, Hanna and Remington (1996) found that color, as a stimulus, is a part of memory representation. Allen (1990) submitted that colors are encoded as a verbal representation as well as in the perceptual mode in the form of a visual image. In a review of literature on the use of color in teaching, Dwyer and Lamberski (1983) conclude that when color is central to the ideas and concepts being presented and the students pay attention, the use of color improves learning.

Power point presentations allow for graphical simulations, which allow for mental imagery and associated knowledge, which should lead to increased learning.

Proponents of power point presentations believe they improve learning through enhanced attention (Luna and McKenzie 1997) improved recall through multimodal benefits, a matching of technologically learning styles with the latest technology.

It should be understood that using PowerPoint in EFL classes does have great advantages both for teachers and students. Catherina (2006) indicates that students think PowerPoint based lectures are more interesting than traditional lectures. Moreover, Fisher (1998) reports that student scores on tests are even improved with PowerPoint lectures as opposed to traditional lectures. Aly, Elen, and Willems (2004) point out that PowerPoint based lectures focus attention and reduce distraction. Szaboa and Hastings (2000) find similar trends in their study at Nottingham Trent University in England. Besides, seventy-two percent of students who are surveyed say that they want PowerPoint presentations to be adopted in EFL classes.

Miltenoff (2003) indicates that PowerPoint can be used as a multimedia and interactive tool. Pictures, animation, sound effects, and music can greatly enhance the quality of the presentation. It is much easier to use attractive fonts, photos, clipart, tables, and graphs in PowerPoint. And the hyperlinks on the slides allow users to get more information than is found in books and broadens the field of view of students. Most importantly, slide shows are adaptable to many EFL teaching environments, including face-to-face and online.

In addition, comparing PowerPoint presentations with handwriting, teachers can immediately appreciate the value and impact of using PowerPoint presentations. According to Coulthard and Hutchinson (1996), "On the one hand, PowerPoint presentations are more effective and they can take less time and effort to create. On the other hand, teachers can improve the quality of PowerPoint presentations while dramatically reducing their production time and budgets." (p. 95).

The colors used in PowerPoint presentations can influence how students respond to teachers' messages. Coulthard and Hutchinson (1996) stated "Colors can bring emotion to PowerPoint presentations. However, used improperly, colors can also undermine themes of teachers' presentations and distract students." (p. 99) In addition, teachers should also be aware that "a significant portion of students - may be color-blind and not perceive the differences between two or more colors. Keeping all these points in mind, teachers are best advised to keep their color selections simple and restrained." (Coulthard\& Hutchinson, 1996).

Coulthard and Hutchinson (1996) indicate that fortunately for teachers, Microsoft hired professional artists to compile PowerPoint's numerous color schemes. A color scheme is a set of eight colors that teachers can apply to individual slides, notes pages, and student handouts. The eight main colors include a background color, title text color, 
text and line color, fill color, shadows color, and three colors for accents .Coulthard and Hutchinson (1996) present the idea that by using color schemes, teachers ensure that all the colors in their presentations are balanced and will work well together. Also, color schemes make it easy to apply a new set of colors to their presentations, just as using templates makes it easy to change overall design.

It has been said that a picture is worth a thousand words. Although this phrase is overused, its truth is undeniable. Coulthard and Hutchinson (1996) indicate that graphics add personality to teacher presentations and convey information more efficiently than text alone. Unfortunately, many new computer users struggle with the tendency to place too many graphics on a single screen. To assist teacher plans of how and when to use graphics, apply these basic principles: strive for simplicity, use emphasis sparingly, and ensure a visual balance between graphics and text.

Coulthard and Hutchinson (1996) find that PowerPoint's Auto Layouts already encourage a balanced and visually appealing use of graphics. The Microsoft ClipArt Gallery mini-app provides a one-stop shopping mall for all the clip art images. A clip art image is a computer graphic or picture that teachers can insert into their documents, usually without having to pay royalties or licensing fees to the artist or designer. Microsoft's ClipArt Gallery provides hundreds of images organized into over 25 categories. Teachers can also use the Gallery to add their own images, delete existing images, and move images.

Although PowerPoint presentations have many advantages, PowerPoint presentations in EFL teaching are hampered by several problems as well.

First, Klemm (2007) thinks that more teachers are just clicking the mouse all the time when they are giving the lectures. Instead of interacting with students during the EFL class, they just sit in front of the computers without leaving their chairs.

Second, Miltenoff (2003) indicates that teachers do not need to write information on the blackboard, but just click the mouse. Therefore, it is very easy for teachers to give too much information in one class, which can difficult for students to comprehend. What's more, students are easily overwhelmed with a large amount of information given in the PowerPoint presentation.

Third, Roblyer (2003) states that students need ample online development time to take full advantage of the benefits of PowerPoint technology. This presents a problem in most EFL classrooms due to insufficient numbers of computers. So educators should try their best to increase the number of computers if conditions permit.

Fourth, integration of PowerPoint technology into the curriculum presents additional problems. Mayer and Moreno (1998) indicate that students need sufficient time to focus, build, and reflect in order to ensure quality projects. The conventional school schedule, often broken into 50-minute blocks, does not lend itself to serious project development. If PowerPoint is going to have a major impact on learning, educators will need to look at ways of infusing more flexibility into students' daily schedules.

Finally, Boyle (1997) warns that technology such as PowerPoint is a mixed blessing. It helps teachers communicate information more quickly, but do not necessarily help them analyze whether or not information is accurate, relevant, or correct. The more information they have, the more important it becomes to learn critical analysis, visual literacy, and information literacy skills.

It should be reiterated that there is a gap about recent studies on the use of Power Point presentations and its effect on learners' writing ability and their attitude. It is hoped this study bridge the gap.

Teaching Writing

There is no doubt that writing is the most difficult skill for L2 learners to master. The difficulty lies not only in generating and organizing idea, but also in translating these ideas into readable text. The skills involved in writing are highly complex. L2 writers have to pay attention to higher level skills of planning and spelling, punctuation, word choice, and so on. The difficulty becomes even more pronounced if their language proficiency is weak.

With so many conflicting theories around and so many implementation factors to consider, planning and teaching a course in writing can be a daunting task.

The writing process as a private activity may be broadly seen as comprising four main stages: planning, drafting, revising and editing. As research has suggested, "many good writers employ a recursive, nonlinear approach-writing of a draft may be interrupted by more planning, and revision may lead to reformulation, with a great deal of recycling to earlier stages"(Krashen, 1984, p. 17).

\section{Process writing}

The term process writing has been bandied about for quite a while in ESL classrooms. It is no more than a writing process approach to teaching writing. The idea behind it is not really to dissociate writing entirely from the written product and to merely lead students through the various stages of the writing process but "to construct processoriented writing instruction that will affect performance" (Freedman, Dyson, Flower, \& Chafe, 1987, p.13). to have an effective performance -oriented teaching program would mean that we need to systematically teach students problemsolving skills connected with the writing process that will enable them to realize specific goals at each stage of the composing process. Thus process writing in the classroom may be construed as a program of instruction which provides students with a series of planned learning experiences to help them understand the nature of writing at every point.

Process writing as a classroom activity incorporates the four basics writing stages - planning, drafting, revising, and editing; and three other stages externally imposed on students by the teacher, namely, responding, evaluating, and post- 
writing. Process writing in the classroom is highly structured as it necessitates the orderly teaching of process skills, and thus it may not, at least, give way to a free variation of writing stages. Teachers often plan appropriate classroom activities that support the learning of specific writing skills at every stage.

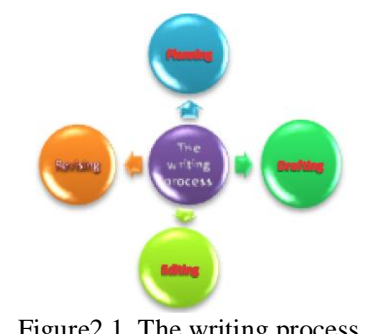

Planning

Pre-writing is any activity in the classroom that encourages students to write. It stimulates thoughts for getting started. In fact, it moves students away from having to face a blank page toward generating tentative ideas and gathering information for writing. The following activities provide the learning experiences for students at this stage:

Group Brain Storming

Group members spew out ideas about the topic. Spontaneity is important here. There are no right or wrong answers. Students may cover familiar ground first and move off to more abstract or wild territories.

Clustering

Students form words related to a stimulus supplies by the teacher. The words are circled and then linked by lines to show discernible clusters. Clustering is a simple yet powerful strategy: "its visual character seems to stimulate the flow of association... and is particularly good for students who know what they want to say but just can't say it" (Proett\& gill, 1989, p.60).

\section{Rapid Free Writing}

Within a limited time of 1 or 2 minutes, individual students freely and quickly write down single words and phrases about a topic. The time limit keeps the writers' minds ticking and thinking fast. Rapid free wring is done when group brain storming is not possible or because the personal nature of a certain topic requires a different strategy.

\section{WH- Questions}

Students generate who, why, what, where, when, and how questions about a topic. More such questions can be asked of answers to the first string of wh-questions, and so on. This can go on indefinitely.

In addition, ideas for writing can be elicited from multimedia sources (e.g., printed material, video, films), as well as from direct interviews, talks, surveys, and questionnaires. Students will be more motivated to write when given a variety of means for gathering information during pre-writing.

\section{Drafting}

Once sufficient ideas are gathered at the planning stage, the first attempt at writing- that is drafting- may proceed quickly. At the drafting stage, the writers are focused on the fluency of writing and are not preoccupied with grammatical accuracy or the neatness of the draft. Depending on the genre of writing (narrative, expository or argumentative), an introduction to the subject of writing may be a startling statement to arrest the reader's attention, a short summary of the rest of the writing, an apt quotation, a provocative question, a general statement, an analogy, a statement of purpose, and so on. Such a strategy may provide the lead at the drafting stage. Once a start is made, the writing task is simplified "as the writers let go and disappear into the act of writing” (D' Aoust, 1989, p. 7).

\section{Responding}

Responding to student writing by the teacher has a central role to play in the successful implementation of process writing. Responding intervenes between drafting and revising. It is the teacher's quick initial reaction to students' drafts. Response van be oral or in writing, after the students have produced the first draft and just before they proceed to revise. The failure of many writing programs in schools today may be ascribed to the fact that responding is done in the final stage when the teacher simultaneously responds and evaluates, and even edits students' finished texts, thus giving students the impression that nothing more needs to be done.

\section{Revising}

When students revise, they review their texts on the basis of the feedback given in the responding stage. They reexamine what was written to see how effectively they have communicated their meanings to the reader. Revising is not merely checking for language errors. It is done to improve global content and the organization of ideas so that the writer's intent is made clearer to the reader.

Editing

At this stage, students are engaged in tidying up their texts as they prepare the final draft for evaluation by the teacher. They edit their own or their peer's work for grammar, spelling, punctuation, diction, sentence structure and accuracy of supportive textual material such as quotation, examples and the like. Editing within process writing is meaningful because students can see the connection between such as an exercise and their own writing in that correction is not done 
for its own sake but as part of the process of making communication as clear and unambiguous as possible to an audience.

\section{Evaluating}

In evaluating student writing, the scoring may be analytical (i.e. based on specific aspects of writing ability) or holistic (i.e. based on a global interpretation of the effectiveness of that piece of writing). In order to be effective, the criteria for evaluation should be made known to students in advance. They should include overall interpretation of the task, sense of audience, relevance, development and organization of ideas, format or layout, grammar and structure, spelling and punctuation, range and appropriateness of vocabulary, nad alacrity of communication.

\section{Post writing}

Post writing constitutes any classroom activity that the teacher and students can do with the completed pieces of writing. This includes publishing, sharing, reading aloud, and transforming texts for stage performances, or merely displaying texts on notice boards. In short, the post writing sage is a platform for recognizing students' work as important and worthwhile.

\section{The Role of Cohesive Devices in Writing}

Halliday and Hasan (1976) have provided a framework for the study of cohesion and coherence in ESL/EFL writing (Green et al., 2000; Jafarpur, 1991; Johns, 1980; Johnson, 1992; Yvette and Yip, 1992; Zhang, 2000). However, the findings of these studies have been somewhat contradictory. Some have found that there is no difference in the deployment of cohesive devices in "good" and "weak" writing (Johnson, 1992; Zhang, 2000).

Others indicate that highly rated essays differ from low rated ones in the use of cohesive devices (Jafarpur, 1991).

According to Johnson (1992), there was no difference in the degree of cohesion between "good" and "weak" compositions written in Malay by native speakers or in English by native and Malay speakers. Zhang's (2000) study of cohesion in 107 expository compositions created by Chinese English majors generated similar findings as Johnson's (1992).

On the other hand, some researchers find that compositions scored holistically high contain more cohesion than those scored low (Jafarpur, 1991). In addition, it is generally agreed that highly rated essays contain more lexical collocations than do low rated essays (Johns, 1980; Zhang, 2000). The researchers also hold that lexical cohesion is the most common category in both good and weak essays, followed by reference and conjunction (Johns, 1980; Zhang 2000). At the same time, some peculiar features have also been identified in the writing of ESL/ EFL learners (Khalil, 1989; Kuo, 1995). Khalil's (1989) analysis showed that the EFL students overused reiteration of the same lexical item as a cohesive device, but underused other lexical and grammatical cohesive devices. The case was the same with the writing composed by Spanish-speaking students (Palmer, 1999) and by Chinese undergraduate English majors (Zhang, 2000). In Wikborg's (1990) study, it was found that Swedish students often showed cohesion problems in their writing ranging from missing or misleading sentence connection to malfunctioning cohesive devices to too great a distance between the cohesive items in a cohesive chain. Consequently, the misuse of these cohesive devices affected or even broke the coherence of the text.

These empirical studies demonstrate that cohesion is an important element of any type of writing and that L1 and L2 learners of English have considerable difficulty in using cohesive devices. To the best of researcher's knowledge there has not been any similar study to investigate the impacts of Power Point presentation slides on cohesive devices used by EFL / ESL students.

\section{Methodology}

\section{A. Participants}

In order to examine the effects of PowerPoint presentations on students' writing and their use of cohesive devices, sixty two BA students from University of Isfahan were randomly assigned into 2 groups .The intended course was "advanced writing. ."Each session lasted 90 minute. One group received the traditional textbook teaching style whereas the other group received the power points of the same materials during ten sessions .It should be mentioned that the same instructor ran all the sessions .

\section{B. Research Design}

This study used both qualitative and quantitative approach .This study benefitted a pretesting, randomization, having experimental and control groups and pretest and posttest, as such it is an experimental study.

TABLE1.

RESEARCH DESIGN OF THE STUDY

\begin{tabular}{lll}
\hline Group pretest & treatment & Posttest \\
\hline EGTOEFL & power point presentations & TOEFL \\
CG $\quad$ TOEFL & conventional method & TOEFL \\
\hline \multicolumn{5}{c}{ EG: Experimental Group } \\
& CG: Control Group
\end{tabular}

\section{Procedure}


The intervention was implemented during the fourth semester of 2009-2010 academic years .In an attempt to assess the effect of applying new technology to the class, a control and treatment group would suffice .The teacher was the same for both groups. The slides highlighted the features of good essay writing .For example how to develop an introduction, a thesis statement, a topic sentence, a conclusion. Slides depicted a sample with enough explanation .A pretest was administered to determine both their proficiency level and their writing skill .The test included grammar items, vocabulary items and reading comprehension items.Also in the writing section of the test, a topic wasassigned to them.Atintervals, the instructor asked questions to assess their learning and asks them to write an essay based on what has been taught.At the end of the semester, a post test were administered .Their scores on the pretest, posttest and their writing were registered for later evaluation. The presentations for control group were supported by traditional, textbased style and the teacher relied on chalk andtalkpresentation .The presentations for treatment group were supported by power point presentations which provide colorful, visual aids with graphics and animation.

It should be mentioned that a placement test consisting of 100 multiple-choice items was employed to determine the proficiency level of the participants and divide them into two groups. This test consisted of four sections including Listening Comprehension, Structure and Written expression items, Vocabulary and Reading Comprehension, and Writing. Due to practicality limitations and because it was not the main construct under investigation in this study, Listening Comprehension of both the placement and TOEFL (criterion against which placement test was validated) was excluded.

\section{TOEFL}

A 1992 original version of TOEFL Test was utilized to serve as a criterion to estimate the concurrent validity of the placement test constructed by the researcher. As to the listening comprehension, the same limitations as the placement test were applied.

\section{Validation Procedure}

Using KR-21, the reliability estimates of the tests were calculated. As to the reliability of post-test, using both KR-20 formula ( Kuder Richardson, 1937), and Cronbach's Coefficient $\alpha$ (Cronbch,1951), the reliability estimates of the test were calculated. Table 2.3 shows reliability indices.

TABLE.3.2

RELIABILITY OF TESTS

\begin{tabular}{lllll}
\multicolumn{5}{c}{ RELIABILITY OF TESTS } \\
\cline { 1 - 3 } Reliability & TOEFL & Placement Test & post test & Alpha \\
\cline { 1 - 2 } & 0.87 & 0.87 & $\mathrm{Kr}-20$ & 0.88 \\
\hline
\end{tabular}

As the table shows, the reliability figures of the test are high enough to be considered as acceptable. It can, therefore, be concluded that the placement test enjoys satisfactory reliability.

After estimating the reliability measures of the above-mentioned test, utilizing the Pearson -Product Moment correlation formula through SPSS software for Windows, the placement test was concurrently validated against the criterion measure, the TOEFL test. The validity coefficient was found to be 0.87 .

TABLE. 3.3.

CONCURRENT VALIDATION OF PLACEMENT TEST AND TOEFL TEST

\begin{tabular}{|lll|}
\hline & CONCURRENT VALIDATION OF PLACEMENT TEST AND TOEFL TEST & Scores of Placement Test \\
\hline Scores of TOEFL test Pearson & \multicolumn{1}{c|}{ Scores of TOEFL Test } & $.866^{* *}$ \\
Correlation & 1.000 & .000 \\
Sig (2-tailed) & 0 & 151 \\
$\mathbf{N}$ & 151 & 1.000 \\
\hline Scores of Placement test & $.866 * *$ & 0 \\
Pearson Correlation & .000 & 151 \\
Sig. (2-tailed) & 151 & \\
$\mathbf{N}$ & $* *$ Correlation is significant at the 0.01 level (2-tailed) \\
\hline
\end{tabular}

\section{FINDINGS}

At the beginning of the study, the pretest was administered to both groups. The results are presented below. According to the pretest scores, there was no difference between CG and EG .

TABLE 4.

PRETEST SCORES ON EG AND CG GROUPS

\begin{tabular}{llll} 
& \multicolumn{3}{l}{ PRETEST SCORES ON EG AND CG GROUPS } \\
\hline Group & $\mathbf{n}$ & M & SD \\
\hline EG & 31 & 15.67 & 1.24 \\
CG & 31 & 12.9 & 0.88 \\
\hline
\end{tabular}

Additionally, pre test scores showed that there was no statistically difference between EG and CG at the beginning of the study. 
At the end of the study, the post test was administered to both groups .Post test scores indicated that group receiving power points outperformed the conventional teaching group .

TABLE5.

POST TEST SCORES ON EG AND CG GROUPS

\begin{tabular}{lcccc}
\hline Group & n & M & SD & p \\
\hline EG & 31 & 20.21 & 4,04 & 0,000 \\
CG & 31 & 15.38 & 4,02 & \\
\hline
\end{tabular}

TABLE 6.

INDEPENDENT-SAMPLES T-TEST ON THE POSTTEST SCORES FOR CONTROL \&EXPERIMENTAL GROUP

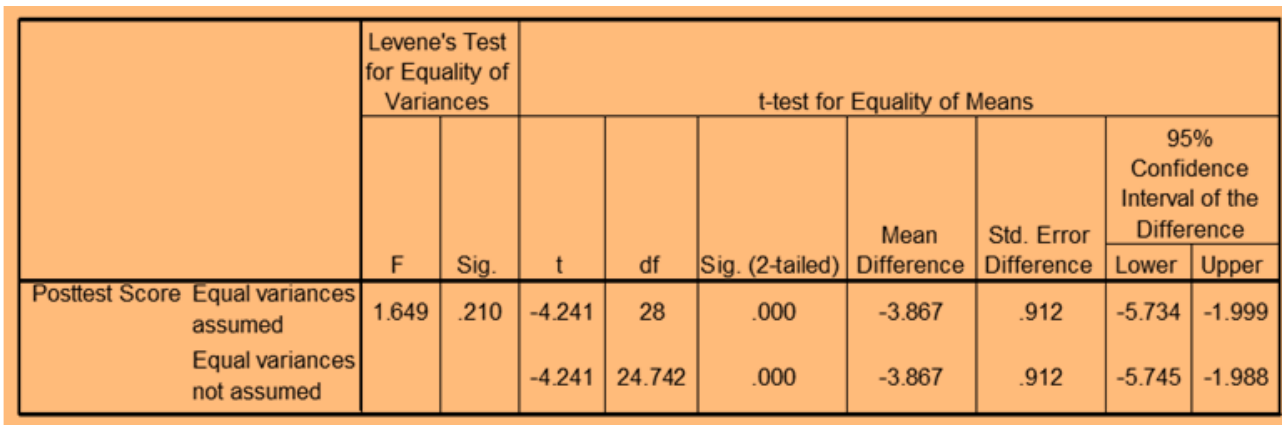

TABLE.7.

COHESIVE DEVICES USED IN POWER POINT PRESENTATION TEACHING STYLE

\begin{tabular}{lllll} 
Type of Cohesive & Reference devices & Conjunction devices & Lexical devices & Total number of \\
devices & & & & 2658 \\
\hline Frequency & 1423 & 698 & 53.16 & 47.79 \\
Mean & 28.46 & 13.96 & 11.75 & 95.88 \\
\hline $\begin{array}{l}\text { Standard deviation } \\
\text { Standard error }\end{array}$ & 11.49 & 5.41 & 1.66 & 23.12 \\
Range & 1.63 & 0.77 & 56 & 3.27 \\
$\begin{array}{l}\text { Percentage based on } \\
\text { total }\end{array}$ & 63 & 30 & $55.6 \%$ & 112 \\
\hline
\end{tabular}

TABLE 8.

COHESIVE DEVICES USED IN TRADITIONAL TEACHING STYLE

\begin{tabular}{|l|l|l|l|l|}
\hline Type of Cohesive devices & Reference devices & Conjunction devices & Lexical devices & $\begin{array}{l}\text { Total number of } \\
\text { cohesive devices }\end{array}$ \\
\hline Frequency & 1223 & 398 & 16.58 & 27.79 \\
\hline Mean & 26.36 & 1.56 & 43.13 & 55.33 \\
\hline Standard deviation & 8.4 & 3.22 & 9.12 & 2.12 \\
\hline Standard error & 0.75 & 0.22 & 0.12 & 1.23 \\
\hline Range & 43 & 22 & 32 & 98. \\
\hline Percentage based on total & 18.98 & 12.34 & 43.32 & $100 \%$ \\
\hline
\end{tabular}

Comparing the performance of two groups based on use of cohesive devices, it became evident that students in power point group performed better than students in traditional teaching style. (frequency use of cohesive devices in power point group is 47.79 and the frequency use of cohesive devices in traditional teaching style is 27.79).

TABLE9

USE OF COHESIVE DEVICES BY BOTH POWER POINT PRESENTATION AND TRADITIONAL TEACHING GROUPS

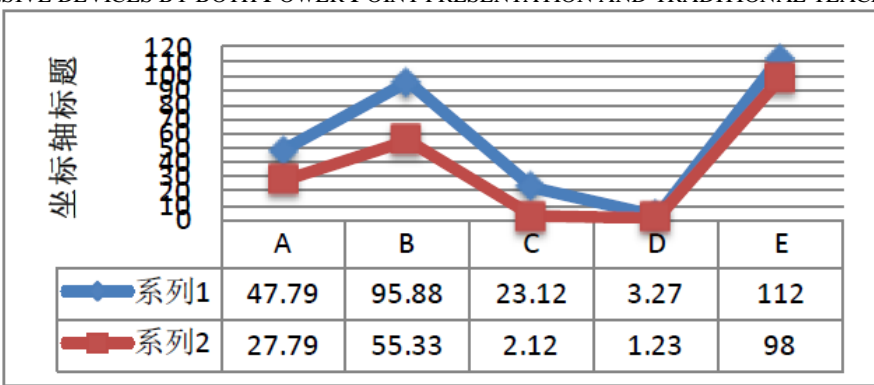

\section{DisCUSSION}

The aim of this study was to systematically investigate Power Point presentations' impacts on EFL settings, the present study aimed to investigate students' academic writing when presentation software Microsoft PowerPoint is 
used. Results indicated that preparing and presenting power point slides would have an effect on EFL student's achievements.Accompanying graphics in slides helped the students construct information in their minds .This construction in their minds could enhance learning. These results also support Mayer's cognitive theory of multimedia learning .According to Mayer, people when learning, place relevant words into auditory working memory and relevant images into visual working memory .People then organize visual information separately in auditory and visual memory and finally integrate these representations with prior knowledge .These results are very meaningful for displaying the advantages of power point to enhance learning.they find it helpful if there are discussion points on the lectures .There is a preference for copies of actual power point slides .Further research could further investigate the use of Power points in other skills and sub-skills. Another study can evaluate the role of Power Point presentations on EFL, ESL children learning foreign languages.

\section{CONCLUSION}

The presentation can be viewed as a process consisting of the appropriate number of preparation stages to make it as effective as possible. Psychologically speaking, each stage has some impact on the learning process and is of equal importance. While assessing students' knowledge the teacher has to consider and evaluate the whole process required to prepare a presentation. On the whole, students need to develop a strategy for structuring their presentations. The introduction of advantages and disadvantages of Power Point presentations helps the teacher to better integrate the presentation into the learning process. Presentations allow students to develop all four skills (i.e. listening, speaking, reading and writing) as in this study the writing skills. Transforming oral presentations into written assignments expands the activity making the presentation more effective. The individual choice of the subject helps to promote successful research strategies and increase motivation. When the researcher compared the results of the participants' writing, the scores revealed that the students in Power Point group outperformed the students in conventional teaching style. Comparing the performance of two groups based on use of cohesive devices, it became evident that students in power point group performed better than students in traditional teaching style.

$\mathrm{s}$ (frequency use of cohesive devices in power point group is 47.79 and the frequency use of cohesive devices in traditional teaching style is 27.79). Therefore it might be a good idea for other researchers to apply Power Point presentations in their teaching styles.

\section{Limitations of the Study}

Throughout the accomplishment of different phases, the study did face some limitations.

1. First, the small and uneven number of participants that we had. Larger samples, hence more representative of the larger population, may yield more conclusive results.

2. Second, there is clearly a need to address the role and impact of Power Point presentation on other language areas.

3. Third, this study was done in an EFL context, so the findings might not be generalized to ESL context.

4. Fourth, it is possible that during this study other intervening variables affected outcomes. As it is believed the difficulty of evaluation along with generalization of findings in human issues. Some uncontrolled variables such as fatigue, unwillingness to participate and effective mood may have affected the results.

5. Fifth, the participants of the study were only English majors in Iran irrespective of their age, and gender. So we cannot extrapolate the findings to other types of studies.

6. According to Singleton (1999) researchers should: be collaborative, be qualitative as well as quantitative, and be durative. This study deals with snapshots of learners, rather than long-term study of language learning over a period of years.

\section{ACKNOWLEDGMENT}

My thanks go to my supervisor, Dr. Saeed Ketabi for his lasting instruction and his valuable hints during this study and to all anonymous participants who took part in my study.

\section{REFERENCES}

[1] Allen, C. K. (1990). Encoding of Colors in Short-Term Memory. Perceptual and Motor Skills, (Vol. 71) pp 211-215.

[2] Aly, M. Elen, J., \&Willems, G. (2004). Instructional multimedia program versus standard lecture: A comparison of two methods for teaching the undergraduate orthodontic curriculum. European Journal of Dental Education, 28- 42

[3] Bartsch, R.A., and K.M. Cobern. (2003). Effectiveness of PowerPoint Presentation in Lectures. Computers\& Education (vol.41) 7 pp. $77-86$

[4] Boyle, T. (1997). Design for multimedia learning. London: Prentice Hall, 24

[5] Butler, J.B., and R.D. Mautz, Jr. (1996). Multimedia Presentations and Learning: A laboratory Experiment. Issues in Education (vol. 11, No.2) 259-280.

[6] Bryant, S. M., and J. E. Hunton. (2000). The Use of Technology in the Delivery of Instruction: Implications for Accounting Educators and Education Researchers. Issues in Accounting Education (Vol. 15, No. 1) pp 129-162.

[7] Cashman, T. J. \& Shelly, G. B. (2000). Microsoft Office 2000: Brief concepts and techniques. America: An International Thomson Publishing Company, 15-17. 
[8] Catherina, F. (2006). Beyond presentation: Using PowerPoint as an effective instructional tool Gifted Child Today, 4 Educator (Vol. 23, No. 4) p3-12

[9] Coulthard, G. J., \& Hutchinson, S. E. (1996). Microsoft PowerPoint 7.0 for Windows 95. America: Tom Casson, 5, 7-8, 90, 95, 99-100, 124-125, 131-132, 158-159, 163-164.

[10] Chamot\& O'Malley. (1987). The Cognitive Academic Language Learning Approach: A Bridge to Mainstream. TESOL Quarterly, p18-28

[11] Clark, J.M., and A..Paivio. (1991). Dual Coding Theory and. Educational Psychology Review (vol.3, No.3) pp.149-210.

[12] Clark, R.E. (1983). Reconsidering research on learning from medial. Review of Educational research (Vol.53, No.4) pp 445459.

[13] Conor, M., and Irene F.H. Wong. (2004). Working Through PowerPoint: A Global Prism for Local Reflections. Business Communication Quarterly (vol: 67, No.2)pp. 228-23

[14] Cook, D. M. (1998). The Power of PowerPoint. Nurse Educator (Vol. 23, No. 4) p5-10.

[15] Dwyer, C. A., and R. J. Lamberski. (1983). A Review of the Research on the Effects of the Use of Color in the TeachingLearning Process. International Journal of Instructional Media (Vol. 10) pp. 303-28.

[16] Eveland, William P., and Sharon Dunwoody.(2001). User Control and Structural Isomorphism or Disorientation and Cognative Load? Communication Research (vol:28)pp. 48-78

[17] Fisher, L. (1998). Using PowerPoint for ESL teaching Retrieved March 10, 2008, from http://iteslj.org/Techniques/FisherPowerPoint.html

[18] Goalkasian Paula. (2000). Pictures, Words, and Sounds: From Which Format Are We Best Able to Reason? Journal of General Psychology (vol:127) pp. 439-45

[19] Hanna, A., and R. Remington. (1996). The Representation of Color and Form in Long-Term Memory. Memory and Cognition (Vol. 24) pp. 322-30.

[20] Harrison, A. (1999). Power Up! Stimulating your Students with PowerPoint .Learning and Leading with Technology (Vol. 26 , No. 4) pp. 2-9.

[21] Hogarty, Kristine Y., Thomas R. Lang, and Jeffery D. Kromney. (2004). Another Look at Technology Use in Classroom: The Development and Validation of an Instrument to Measure Teachers' Perceptions. Educational and psychological measurement (vol:63) pp. 139-168

[22] Hogarty, Lang, and Kromney (2003). Some Linguistic Differences in the Written English of Chinese and Inter language Texts : a corpus-based enquiry. English for Specific Purposes (vol.36) pp.19, 99-113.

[23] Jafarpur, A., (1991). Cohesiveness as a basis for evaluating compositions. System (vol: 19),pp. 459-465.

[24] Klemm, W. R. (2007). Computer slide shows: A trap for bad teaching. College Teaching pp. 45-50.

[25] Mayer, R., \& Moreno, R. (1998). A split attention effect in multimedia learning: Evidence for dual processing systems in working memory. Journal of Educational Psychology, 90(2), 312-313

[26] Miltenoff, P. (2003). Teaching with technology: Multimedia and interactivity, (vol: 43)pp. 12-23.

[27] NEXUS: The Convergence of Language Teaching and Research Using Technology. CALICO Monograph Series, Volume 4.

[28] Stemler, L. (1997). Educational characteristics of multimedia: A literature review. Journal of Educational Multimedia and Hypermedia, 6(3-4), 339-341.

[29] Roblyer, M. D. (2003, December 12). Integrating educational technology into teaching (3rd ed.) The United States: Jeffery W. Johnston, 167, 179.

[30] Szaboa, A., \& Hastings, N. (2000). Using IT in the undergraduate classroom: Should we replace the blackboard with PowerPoint? Computers and Education, 32,(vol:18)pp.23-30

[31] Yu, Y., (2000). Helping EFL Students Learn to Write Through Feedback. Teaching English in China (vol:)pp.23, 55-59.

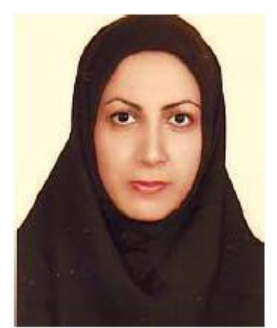

Soraya Rajabi was born in Iran-Esfahan in 21.03.1985. She receives her BA in English translation from Khorasgan University in Esfahan, Iran in 2008. Then she got her MA in teaching English from University of Esfahan, Iran in 2011.

She also teaches English to EFL students in Iran. She has been teaching English for five years in the branch of Isfahan University of Technology. She teaches both general and specific English. She is teaching English also in a University in Esfahan, Iran to the students of engineering. She has also published an article under the title of "DON'T JUDGE A BOOK BY ITS COVER: TEXT BOOK EVALUATION IN THE EFL SETTINGS", Uluslararası Sosyal Ara tırmalar Dergisi .The Journal of International Social Research.Volume: 3 Issue: 14 Fall 2010. She is interested in CALL, Testing and Assessment, Teaching English to EFL students, ESP. Relevant to these research areas she is working on some papers. Mrs. Rajabi has published an article in the journal of social research and she has got an acceptance from to ED-MEDIA 2011--World Conference on Educational Multimedia, Hypermedia \& Telecommunications in Lisbon, Portugal, June 27-July 1, 2011.

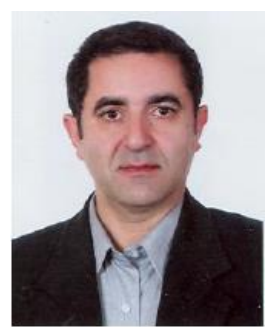

Saeed Ketabi has a Ph.D. in Applied Linguistics from the University of Cambridge, England and is currently teaching various ELT courses at the Faculty of Foreign Languages of the University of Isfahan. He has published more than forty articles and 15 books (ketabi@fgn.ui.ac.ir: s.ketabi@yahoo.com) 